\title{
Speciation analysis of mercury in seafood by using high-performance liquid chromatography on-line coupled with cold-vapor atomic fluorescence spectrometry via a post column microwave digestion
}

\author{
Li-Na Liang ${ }^{\text {a }}$, Gui-Bin Jiang ${ }^{\mathrm{a}, *}$, Jing-Fu Liu ${ }^{\mathrm{a}}$, Jing-Tian $\mathrm{Hu}^{\mathrm{b}}$ \\ ${ }^{a}$ Research Center for Eco-Environmental Sciences, Chinese Academy of Sciences, P.O. Box 2871, Beijing 100085, China \\ b Department of Chemistry, Shan Dong University, Jinan 250100, China
}

Received 28 June 2002; received in revised form 22 October 2002; accepted 28 October 2002

\begin{abstract}
An automatic system, based on the on-line coupling of high-performance liquid chromatography (HPLC) separation, post column microwave digestion, and cold-vapor atomic fluorescence spectrometry (CVAFS) detection, was proposed for the speciation analysis of four mercury compounds. Post column microwave digestion, in the presence of potassium persulfate (in $\mathrm{HCl}$ ), was applied in the system to improve the conversion efficiency of three organic mercury compounds into inorganic mercury. Parameters influencing the on-line digestion efficiency and the separation effect were optimized. To avoid water vapor and methanol entering into the atomic fluorescence detector, ice-water mixture bath was used to cool the microwave-digested sample solution. Four mercury species including inorganic mercury chloride (MC), methylmercury chloride (MMC), ethylmercury chloride (EMC) and phenylmercury chloride (PMC) were baseline separated within 13 min by using RP $\mathrm{C}_{18}$ column with a mobile phase of $50 \%(\mathrm{v} / \mathrm{v})$ methanol containing $10 \mathrm{mmol}^{-1}$ tetrabutyl ammonium bromide and $0.1 \mathrm{moll}^{-1}$ sodium chloride pumped at $1.2 \mathrm{ml} \mathrm{min}^{-1}$. Seafood samples, composed of three gastropod species and two bivalve species from Yantai port, China, have been analyzed by the proposed method. Dogfish muscle (DORM-2) was analyzed to verify the accuracy of the method and the result was in good agreement with the certified value.
\end{abstract}

(C) 2002 Published by Elsevier Science B.V.

Keywords: Microwave digestion; Speciation; Mercury; HPLC; CVAFS

\section{Introduction}

Inorganic and organic mercury compounds, among the most important global environmental pollutants, was given public concern all the while since the Minamata Bay disaster in 1956 [1]. Owing to the contents of mercury involved in environmental matrices

\footnotetext{
* Corresponding author. Fax: +86-10-62923563.

E-mail address: gbjiang@mail.rcees.ac.cn (G.-B. Jiang).
}

are usually very low, and their toxic properties are species dependent, sensitive and specific methods are always imperative for the last several decades.

In view of the analytical approaches for the speciation analysis of inorganic and organic mercury compounds, HPLC is superior to GC when dealing with low volatile and polar mercury compounds. However, UV detector as a common HPLC detector often gives relatively poor sensitivity towards inorganic and organic mercury [2]. Recently, analytical 
methods based on HPLC on-line or off-line hyphenation with element-specific detection methods such as atomic absorption spectrometry (AAS) [3], inductively coupled plasma mass spectrometry (ICP-MS) [4] have been used as routine techniques. Although the cold-vapor atomic fluorescence spectrometry (CVAFS) offers simple, sensitive and cost-effective operation, it has not been used as a universal detector for the speciation analysis of mercury compounds yet. Traced from literature, only several groups $[5,6]$ utilize atomic fluorescence spectrometry as a specific detector for HPLC for mercury speciation, which adopted post column ultraviolet (UV) irradiation to oxidize organic mercury to inorganic mercury.

Direct introduction of organic mercury, eluted from the HPLC analytical column, into the detector was often suffered from low sensitivity. On-line post column oxidation is thus commonly adopted to get higher sensitivity. At present, chemical oxidation and UV irradiation technique for on-line post column oxidation of mercury compounds have been reported. Various oxidants, including $\mathrm{KBr} / \mathrm{KBrO}_{3}$ [6], $\mathrm{K}_{2} \mathrm{~S}_{2} \mathrm{O}_{8}$ [5,7], $\mathrm{K}_{2} \mathrm{Cr}_{2} \mathrm{O}_{7}$ [8-10] have been used. The $\mathrm{KBr} / \mathrm{KBrO}_{3}$ [6] oxidization procedures has the advantage of being conducted at room temperature but suffered from relatively long reaction time and potential fluorescence quench effect. Falter et al. adopted UV irradiation [11-13] to decompose organic mercury. To our knowledge, the on-line post column microwave digestion has not been used to digest organic mercury.

This paper describes an automatic system for the speciation analysis of four mercury compounds. Post column microwave digestion, in the presence of potas- sium persulfate (in $\mathrm{HCl}$ ), was applied in the system to improve the conversion efficiency of three organic mercury compounds into inorganic mercury. The using of ice-water mixture bath for on-line cooling of the digestion solution effectively avoided water vapor and methanol entering into the atomic fluorescence detector and thus reduced the fluorescence quench effect [14].

\section{Experimental}

\subsection{Instrumentation}

The schematic diagram of the hyphenation system is shown in Fig. 1. Sample was injected by a Rheodyne model 7725 injection valve with a $20 \mu$ l sample loop (Rheodyne, Cotati, CA, USA) and the mobile phase was delivered by a LC-10AT vp (Shimadzu, Japan) pump. The HPLC separation was achieved by using a Shim-pack CLC-ODS column $(150 \mathrm{~mm} \times 6 \mathrm{~mm}$ i.d., $10 \mu \mathrm{m})$. The HPLC effluent converged with $\mathrm{K}_{2} \mathrm{~S}_{2} \mathrm{O}_{8}$ (in $\mathrm{HCl}$ ), delivered by a peristaltic pump, and entered into a polytetrafluoroethylene (PTFE) tube ( $3 \mathrm{~m} \times 0.5 \mathrm{~mm}$ i.d.). The coiled PTFE tube was placed in a $700 \mathrm{~W}$ domestic microwave oven Glanze $^{\mathrm{TM}}$ purchased from local retail store) set at low power range to digest samples. The effluent of the decomposed compounds from the microwave oven was cooled down through an ice-water bath and then reacted with $\mathrm{KBH}_{4}$ solution introduced by a peristaltic pump. The mercury vapor generated in the reaction was separated in a gas-liquid separator by argon gas

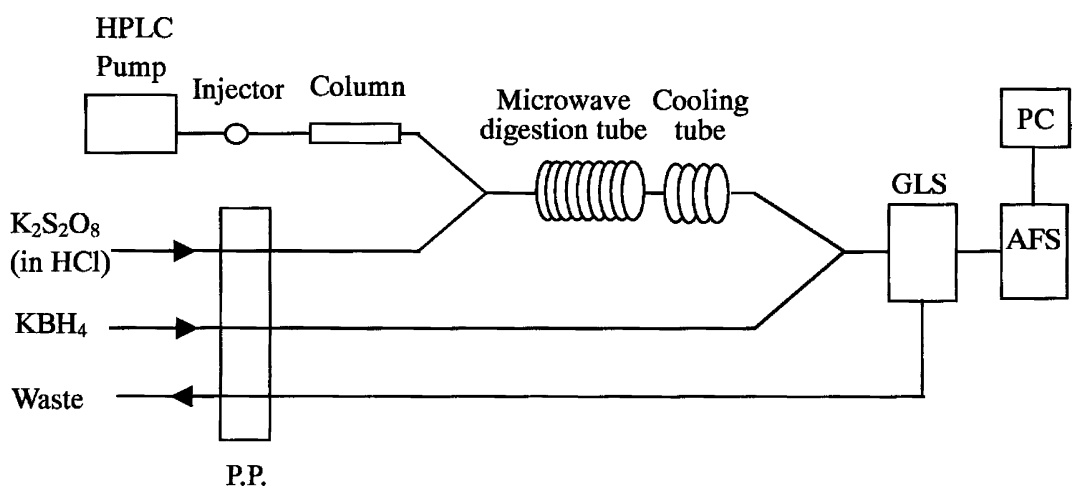

Fig. 1. Schematic diagram of hyphenation of HPLC and AFS. 
Table 1

Experimental condition for HPLC and CVAFS

\begin{tabular}{|c|c|}
\hline \multicolumn{2}{|l|}{ HPLC } \\
\hline Column & $\begin{array}{l}\text { CLC-ODS column, } 150 \\
\times 6 \mathrm{~mm} \text { i.d., } 10 \mu \mathrm{m}\end{array}$ \\
\hline Mobile phase & $\begin{array}{l}50 \% \text { (v/v) } \mathrm{CH}_{3} \mathrm{OH}: 10 \mathrm{~m} \mathrm{moll}^{-1} \\
\text { TBA: } 0.1 \mathrm{moll}^{-1} \mathrm{NaCl}\end{array}$ \\
\hline Mobile phase flow rate & $1.2 \mathrm{ml} \mathrm{min}^{-1}$ \\
\hline Sample injection & $20 \mu 1$ \\
\hline \multicolumn{2}{|l|}{ On-line digestion } \\
\hline Microwave & Low power \\
\hline Digestion coil & PTFE tube, $3 \mathrm{~m} \times 0.5 \mathrm{~mm}$ i.d. \\
\hline Oxidant solution & $\begin{array}{l}1 \%(\mathrm{~m} / \mathrm{v}) \mathrm{K}_{2} \mathrm{~S}_{2} \mathrm{O}_{8} \text { (in } 10 \% \mathrm{HCl} \text { ), } \\
1.4 \mathrm{ml} \mathrm{min}^{-1}\end{array}$ \\
\hline \multicolumn{2}{|l|}{ Hydride generation } \\
\hline Reducing solution & 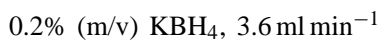 \\
\hline \multicolumn{2}{|l|}{ AFS } \\
\hline Lamp & $\begin{array}{l}\text { Hollow cathod mecury lamp, } \\
253.7 \mathrm{~nm}\end{array}$ \\
\hline PMT voltage & $280 \mathrm{~V}$ \\
\hline Primary current & $40 \mathrm{~mA}$ \\
\hline Carrier gas & Argon, $200 \mathrm{ml} \mathrm{min}^{-1}$ \\
\hline
\end{tabular}

and atomized in a quartz atomizer warmed by infrared radiation. Determinations were performed by a model AF-610A non-dispersive atomic fluorescence spectrometer (Beijing Raileigh Analytical Instrument Co.) at $253.7 \mathrm{~nm}$ line source with a specially made hollow cathode lamp (Beijing Tian-gong analytical instrument factory) operating at $280 \mathrm{~V}$ of PMT voltages and $40 \mathrm{~mA}$ of lamps current. A personal computer installed with a lab-compiled software was used for the control of the AFS and to integrate the peak areas. The experimental conditions are listed in Table 1.

\subsection{Reagents and standards}

All chemicals were of analytical grade except where specified and de-ionized water was used throughout. Stock solution of standard inorganic mercury $\left(1 \mathrm{mg} \mathrm{ml}^{-1}\right.$ as $\mathrm{Hg}$ ) was prepared by dissolving appropriate amount of $\mathrm{HgCl}_{2}$ (MC, Merck-Schuchardt) in $5 \%(\mathrm{v} / \mathrm{v}) \mathrm{HNO}_{3}$. Stock solutions of standard organomercury chloride $\left(1 \mathrm{mg} \mathrm{ml}^{-1}\right.$ as $\left.\mathrm{Hg}\right)$ were prepared by dissolving appropriate amounts of methylmercury chloride $\left(\mathrm{CH}_{3} \mathrm{HgCl}, \mathrm{MMC}\right)$, ethylmercury chloride $\left(\mathrm{C}_{2} \mathrm{H}_{5} \mathrm{HgCl}, \mathrm{EMC}\right)$ and phenylmercury chloride $\left(\mathrm{C}_{6} \mathrm{H}_{5} \mathrm{HgCl}\right.$, PMC) (Merck-Schuchardt), respectively, in methanol. Working solutions were obtained by dilution with methanol and prepared daily before use. All solutions were stored at $4{ }^{\circ} \mathrm{C}$ in refrigerator.

Aqueous solutions, $0.1 \mathrm{moll}^{-1}$ tetrabutyl ammonium bromide (TBA) and $1 \mathrm{moll}^{-1} \mathrm{NaCl}$, were prepared weekly and stored at $4{ }^{\circ} \mathrm{C}$ in refrigerator. Daily-prepared HPLC mobile phase was a mixture of appropriate TBA, $\mathrm{NaCl}$ solution, water and $\mathrm{CH}_{3} \mathrm{OH}$ and filtered through a $0.45 \mu \mathrm{m}$ membrane filter before use.

Acidic potassium bromide solution: $90 \mathrm{~g}$ of $\mathrm{KBr}$ was dissolved in $100 \mathrm{ml}$ water and $25 \mathrm{ml}$ of concentrated $\mathrm{H}_{2} \mathrm{SO}_{4}$ was added in $50 \mathrm{ml}$ water. After cooling to the room temperature, the two solutions were mixed and diluted to $500 \mathrm{ml}$ with de-ionized water.

A $1 \mathrm{moll}^{-1} \mathrm{CuSO}_{4}$ solution and $10 \mathrm{mmoll}^{-1}$ $\mathrm{Na}_{2} \mathrm{~S}_{2} \mathrm{O}_{3}$ solution was prepared by dissolving $25 \mathrm{~g}$ $\mathrm{CuSO}_{4} \cdot 5 \mathrm{H}_{2} \mathrm{O}$ and $0.2482 \mathrm{~g} \mathrm{Na}_{2} \mathrm{~S}_{2} \mathrm{O}_{3} \cdot 5 \mathrm{H}_{2} \mathrm{O}$ separately in $100 \mathrm{ml}$ water and stored at $4{ }^{\circ} \mathrm{C}$ in refrigerator.

A $0.2 \%(\mathrm{~m} / \mathrm{v}) \mathrm{KBH}_{4}$ solution was prepared daily by dissolving $1 \mathrm{~g} \mathrm{KBH}_{4}$ in $500 \mathrm{ml}$ of $0.2 \%(\mathrm{~m} / \mathrm{v}) \mathrm{KOH}$. An oxidant solution of $1 \%(\mathrm{~m} / \mathrm{v}) \mathrm{K}_{2} \mathrm{~S}_{2} \mathrm{O}_{8}$ solution was prepared in $10 \%(\mathrm{v} / \mathrm{v}) \mathrm{HCl}$.

\subsection{Sample preparation}

Samples were prepared with referencing to literature [15]. Briefly, to 1.0-2.0 g well-proportioned wet samples in a $50 \mathrm{ml}$ centrifuge tube, was added $3 \mathrm{ml}$ $25 \%(\mathrm{~m} / \mathrm{v}) \mathrm{KOH}$ (in methanol) and shaking mechanically overnight. Then $3 \mathrm{ml}$ of $6 \mathrm{moll}^{-1} \mathrm{HCl}, 4 \mathrm{ml}$ of acidic $\mathrm{KBr} / \mathrm{CuSO}_{4}(3: 1)$ and $5 \mathrm{ml}$ of $\mathrm{CH}_{2} \mathrm{Cl}_{2}$ were added into the tube in sequence, shaking for $2 \mathrm{~h}$ to extract organic mercury into the $\mathrm{CH}_{2} \mathrm{Cl}_{2}$ phase. After centrifuging at $2000 \mathrm{rpm}$ for about $10 \mathrm{~min}$, the $\mathrm{CH}_{2} \mathrm{Cl}_{2}$ phase was transferred into a 7-ml glass tube and extracted with $1 \mathrm{ml}$ sodium thiosulfate. Shaking $45 \mathrm{~min}$ was needed to hasten the extraction speed. Setting for a few minutes for phase separation, the water phase was pipetted and injected directly into the HPLC-MD-AFS system for the separation and determination.

\section{Results and discussion}

\subsection{Optimization of mobile phase}

Experiments showed that while the methanol content in the mobile phase influenced slightly the 
resolution of methylmercury and ethylmercury, it influenced significantly the resolution of inorganic mercury and phenylmercury. When the methanol content in the mobile phase was $50 \%$, the resolutions were all in the range of $0.9-1.4$, which were almost lied in the optimum value $(1-1.5)$. When the methanol content lower or higher than $50 \%$, the resolution Rs $\gg 1.5$ (about 2.6) or $<0.6$, which were unbearable in chromatogram. On the other hand, higher concentration of methanol in the mobile phase increased the chance of methanol vapor entering into the AFS atomizer that increased the fluorescence quench effect. Therefore, $50 \%$ methanol was adopted as optimum.

TBA in the mobile phase was used as an ion-pair reagent and its concentration was optimized from 0 to $20 \mathrm{mmoll}^{-1}$. As reported by Ho and Uden [2], the concentration of TBA influenced the retention behavior of inorganic mercury significantly while gave little effect on that of organic mercury. Fig. 2 showed the effect of TBA concentration on the retention time of the four studied mercury compounds. As can be seen, the TBA concentration significantly influenced the retention time of MC. This is due to the higher stability of $\left[\mathrm{HgCl}_{4}\right]^{2-}$ that makes it requires a great amount of ion-pair reagent for completing ion-pair formation. The separation of mercury compounds can be greatly changed by varying the TBA concentration and good results were obtained when $10 \mathrm{mmoll}^{-1}$ TBA was used. In the following studies, $10 \mathrm{mmol}^{-1}$ TBA was thus adopted as optimum.

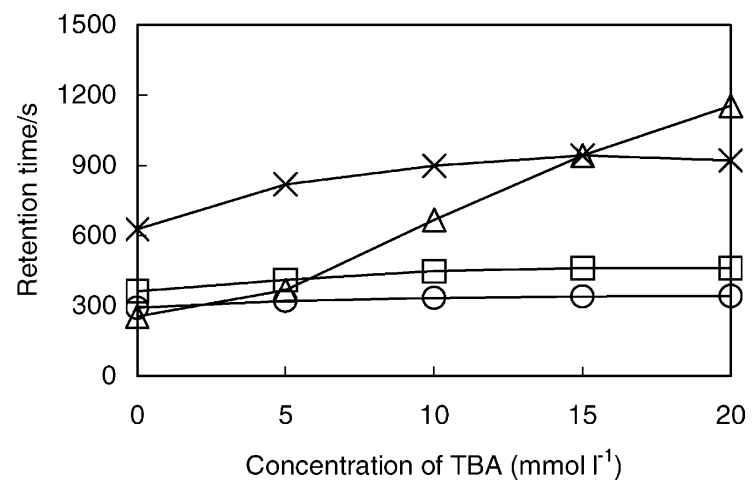

Fig. 2. Effect of the TBA concentration on the retention time of mercury compounds. Marks identified as: $(\bigcirc)$ MMC; $(\square)$ EMC; $(\triangle) \mathrm{MC} ;(\times)$ PMC. Each mercury species was present at $10 \mathrm{ng}$. Other conditions were given in Table 1.

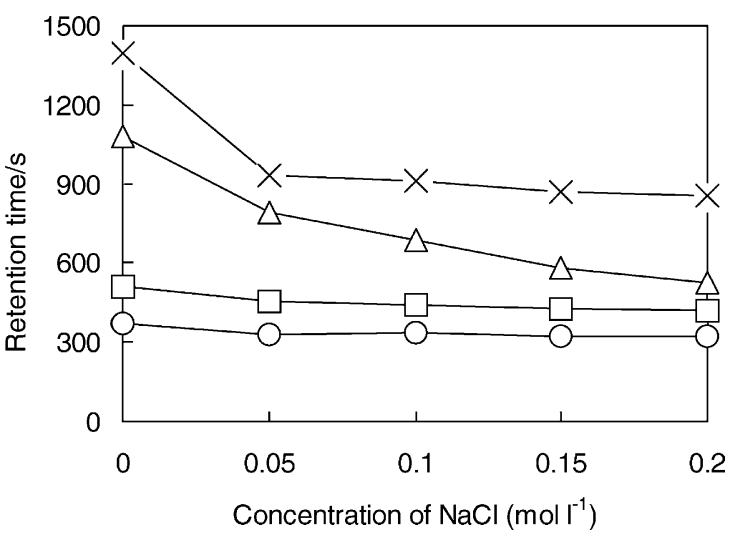

Fig. 3. Effect of the $\mathrm{NaCl}$ concentration on the retention time of mercury compounds. Marks identified as: $(\bigcirc)$ MMC; $(\square)$ EMC; $(\triangle) \mathrm{MC} ;(\times)$ PMC. Each mercury species was present at $10 \mathrm{ng}$. Other conditions were given in Table 1 .

Another parameter that affecting the separation of mercury compounds was $\mathrm{NaCl}$ concentration. As shown in Fig. 3, the addition of $\mathrm{NaCl}$ into the eluent resulted in little abatement of retention time for organic mercury but sharp decreasing of that for MC. This probably is due to the formation of more stable $\left[\mathrm{HgCl}_{4}\right]^{2-}$ that resulted in greatly increasing of MC solubility, while organic mercury formed singly negative charged complexes $\left(\mathrm{RHgCl}_{2}{ }^{-}\right)$.

As the introduction of oxidant solution for post column microwave digestion resulted in dilution of mercury compounds eluting from the HPLC column, the flow rate of mobile phase not only determined the retention time of mercury compounds but also influenced the sensitivity of the method. Higher flow rate of mobile phase would keep the dilution effect in the minimum level, which was helpful for obtaining higher sensitivity. However, the optimal separation could not be obtained if the flow rate was too higher. A flow rate of $1.2 \mathrm{ml} \mathrm{min}^{-1}$ was selected for further experiment.

\subsection{Microwave digestion}

Comparing with the commonly used digestion method, microwave digestion has the advantage of rapid and effective decomposition of the organic mercury to inorganic form. Therefore, post column microwave digestion was adopted in this study.

The influence of PTFE digestion tube dimension on the digestion efficiency was investigated in detail. 
When a $3 \mathrm{~m} \times 0.7 \mathrm{~mm}$ i.d. PTFE tube was used as digestion tube, organic mercury could be decomposed completely into inorganic mercury. However, the peaks of MC, MMC and EMC overlapped and no separation could be obtained. While the $7 \mathrm{~m} \times 0.3 \mathrm{~mm}$ i.d. PTFE tube could not decompose the organic mercury efficiently. Increasing the length of the $0.3 \mathrm{~mm}$ i.d. PTFE tube might give efficient digestion, but it caused high system pressure, which made it impossible for the peristaltic pump of the AFS to deliver the oxidant solution into the flow system. Therefore, $0.5 \mathrm{~mm}$ i.d. PTFE tube was adopted as a compromise. Experiments show that organic mercury could be completely digested with a $3 \mathrm{~m} \times 0.5 \mathrm{~mm}$ i.d. PTFE tube. Shorter length of PTFE tube was insufficient for complete decomposition while longer tube had no effect on the decomposition efficient but resulted in diffusion of separated mercury compounds. A $3 \mathrm{~m} \times 0.5 \mathrm{~mm}$ i.d. PTFE tube was adopted as optimum in this study.

To prevent the water vapor and methanol entering the third gas-liquid separator of AFS, an ice-water mixture bath was used to cool digested sample solution as shown in Fig. 1. Experiment showed that no kinetic abatement of the cold-vapor generation reaction was observed even the temperature was dropped to $0{ }^{\circ} \mathrm{C}$, which is in agreement with the result of Hintelmann and Wilken [5].

According to our previous study [16], it takes 20 min to oxidize organic mercury completely into inorganic mercury within boiling water bath when $\mathrm{K}_{2} \mathrm{~S}_{2} \mathrm{O}_{8}$ (in $\mathrm{HCl}$ ) was used as oxidant. In this study, the decomposition time was reduced to about $20 \mathrm{~s}$ with the application of microwave digestion and the conversion efficiency would be much lower if microwave digestion was absent. The concentration of $\mathrm{K}_{2} \mathrm{~S}_{2} \mathrm{O}_{8}$ had significant effect on method sensitivity. Low concentration of $\mathrm{K}_{2} \mathrm{~S}_{2} \mathrm{O}_{8}$ could not decompose organic mercury completely while high concentration of it influenced the sensitivity, as the excess of $\mathrm{K}_{2} \mathrm{~S}_{2} \mathrm{O}_{8}$ would react with $\mathrm{KBH}_{4}$ in the subsequent reduction tube. Using MMC as a model compound, the concentration of $\mathrm{K}_{2} \mathrm{~S}_{2} \mathrm{O}_{8}$ was optimized at different concentration of $\mathrm{KBH}_{4}$. Results shown in Fig. 4 indicate that the highest sensitivity was obtained when $1 \% \mathrm{~K}_{2} \mathrm{~S}_{2} \mathrm{O}_{8}$ and $0.2 \% \mathrm{KBH}_{4}$ were used. Therefore, $1 \% \mathrm{~K}_{2} \mathrm{~S}_{2} \mathrm{O}_{8}$ and $0.2 \% \mathrm{KBH}_{4}$ were adopted as optimum.

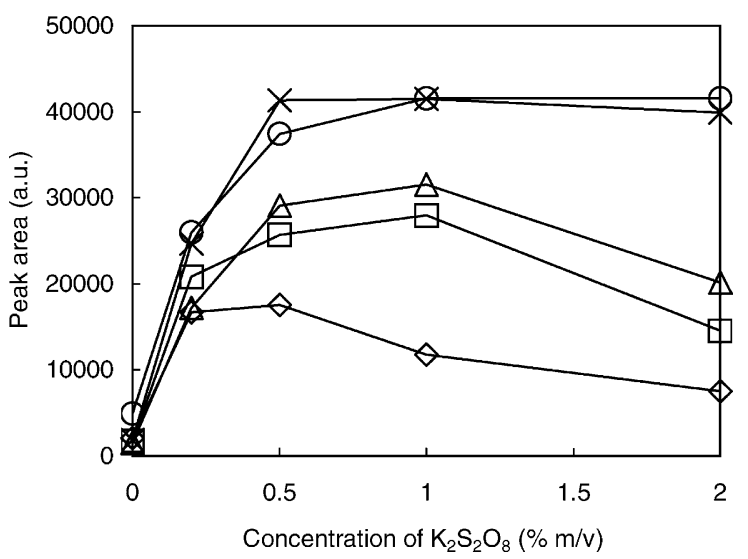

Fig. 4. Effect of the $\mathrm{K}_{2} \mathrm{~S}_{2} \mathrm{O}_{8}$ and $\mathrm{KBH}_{4}$ concentration on the fluorescence intensity of mercury compounds. Marks identified as: $(\diamond) 0.01 \% \mathrm{KBH}_{4} ;(\square) 0.05 \% \mathrm{KBH}_{4} ;(\triangle) 0.1 \% \mathrm{KBH}_{4} ;(\times)$ $0.2 \% \mathrm{KBH}_{4}$; (○) $0.5 \% \mathrm{KBH}_{4}$. MMC injected was $10 \mathrm{ng}$. Other conditions were given in Table 1.

\subsection{Optimization of cold-vapor generation}

The concentration of $\mathrm{KBH}_{4}$ and $\mathrm{HCl}$ were the two decisive factors affecting the cold-vapor generation reaction efficiency. The presence of $\mathrm{HCl}$ not only provided an acidic media for the cold-vapor generation but also be important for the decomposition of organic mercury. As the $\mathrm{KBH}_{4}$ concentration was optimized in the above experiment, only the $\mathrm{HCl}$ concentration was optimized in this part. The optimized results were shown in Table 1.

\subsection{Mercury speciation and figures of merit}

A typical chromatogram of MMC, EMC, MC and $\mathrm{PMC}$ at $10 \mathrm{ng}$ levels, obtained with a mobile phase of $50 \% \mathrm{CH}_{3} \mathrm{OH}$ containing $10 \mathrm{~m} \mathrm{moll}^{-1}$ TBA and $0.1 \mathrm{moll}^{-1} \mathrm{NaCl}$ pumped at $1.2 \mathrm{ml} \mathrm{min}^{-1}$, is shown in Fig. 5. As can be seen, the four mercury compounds were fully resolved and the separation was complete in $13 \mathrm{~min}$. Broadening of the peaks is resulted from the post column dilution effect. Better separation can be obtained by improving the performance of the pump for introducing oxidant solution into the flow system thus making long $0.3 \mathrm{~mm}$ i.d. tube to be used for microwave digestion possible.

Table 2 shows some characteristics of the proposed method. The linearity of the four mercury compounds 


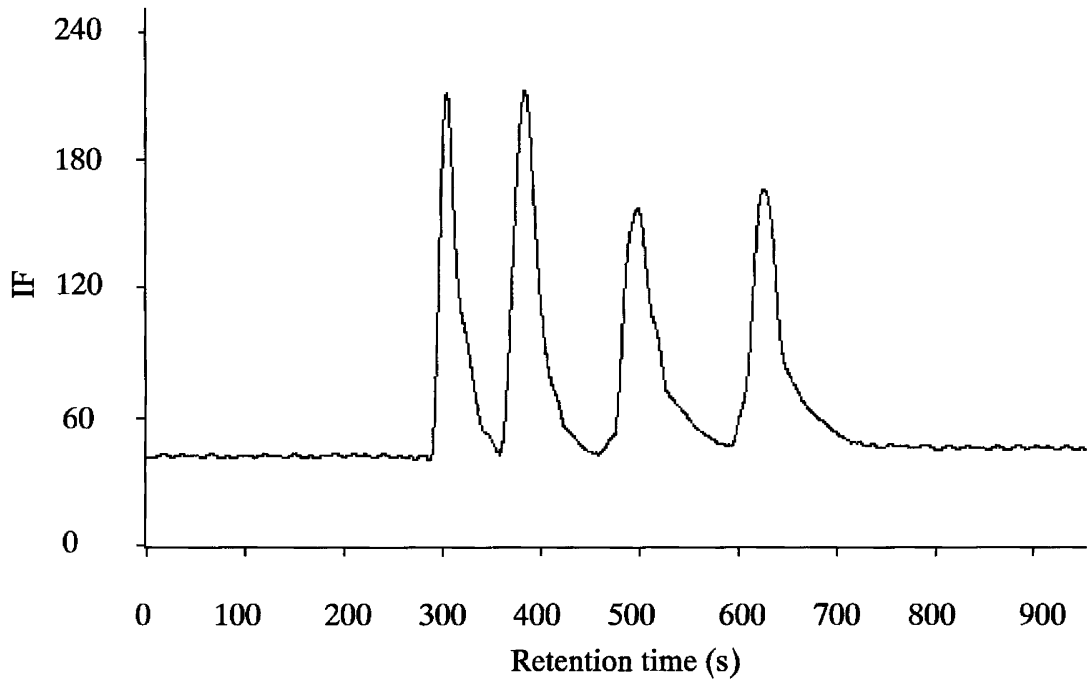

Fig. 5. Chromatogram of four mercury compounds using a $50 \%(\mathrm{v} / \mathrm{v})$ methanol mobile phase containing $10 \mathrm{mmol}^{-1} \mathrm{TBA}$ and $0.1 \mathrm{~mol} \mathrm{l}^{-1}$ $\mathrm{NaCl}$ at flow rate of $1.2 \mathrm{ml} \mathrm{min}{ }^{-1}$. Each mercury species was present at $10 \mathrm{ng}$.

Table 2

Standard calibration curve and linear range of mercury compounds

\begin{tabular}{lllll}
\hline Compounds & Calibration curve & $\begin{array}{l}\text { Relation } \\
\text { coefficient }\end{array}$ & $\begin{array}{l}\text { Linear } \\
\text { range (ng) }\end{array}$ & $\begin{array}{l}\text { Detection } \\
\text { limit (ng) }\end{array}$ \\
\hline MC & $Y=3987.8 X-2392.6$ & 0.9985 & $0.4-100$ & 0.30 \\
MMC & $Y=3972.2 X-2129.9$ & 0.9996 & $0.4-100$ & 0.20 \\
EMC & $Y=5022.4 X-4338.4$ & 0.9987 & $0.4-100$ & 0.17 \\
PMC & $Y=5530.6 X-6655.6$ & 0.9937 & $0.4-100$ & 0.14 \\
\hline
\end{tabular}

was ranged from 0.4 to $100 \mathrm{ng}$. The absolute detection limits based on three levels of the background were $0.20 \mathrm{ng}$ for MMC, $0.17 \mathrm{ng}$ for $\mathrm{EMC}, 0.30 \mathrm{ng}$ for $\mathrm{MC}$ and $0.14 \mathrm{ng}$ for PMC, respectively.

\subsection{Validation of the method and application}

Certified reference material Dogfish muscle (DORM-2) was analyzed to validate the method.

Table 3

Results of MMC contents in DORM-2 and seafood samples

\begin{tabular}{lcc}
\hline Sample & $\begin{array}{l}\text { MMC concentration } \\
\left(\text { mean }^{\mathrm{a}} \pm \text { S.D. }{ }^{\mathrm{b}}, \mathrm{ng} \mathrm{g}^{-1}\right)\end{array}$ & $\begin{array}{l}\text { Certified values } \\
\left(\mathrm{mean}^{\mathrm{a}} \pm \mathrm{S}^{\mathrm{D}} .^{\mathrm{b}}, \mathrm{ng} \mathrm{g}^{-1}\right)\end{array}$ \\
\hline Sinonovacula constrica & $16.36 \pm 0.86$ & - \\
Mya arenaria & $18.95 \pm 0.84$ & - \\
Neverita didyma & $50.61 \pm 2.10$ & - \\
Neptunea arthritica cumingii & $31.18 \pm 0.86$ & - \\
Rapana venosa & $68.56 \pm 2.87$ & - \\
Dogfish muscle (DORM-2) & $4236.74 \pm 143.09$ & $4470 \pm 320$ \\
\hline
\end{tabular}

\footnotetext{
${ }^{\mathrm{a}} n=3$.
}

${ }^{\mathrm{b}}$ Standard deviation. 
As shown in Table 3, the experiment result was in good agreement with the certified value. The proposed method was applied to speciation of mercury in seafood collected from the coast of Yantai port in China. As shown in Table 3, only the methylmercury was detected with concentration ranged from 16.36 to $68.56 \mathrm{ng} \mathrm{g}^{-1}$ of mercury.

\section{Conclusions}

A novel automatic system, based on the on-line coupling of HPLC separation, post column microwave digestion, and CVAFS detection, for the speciation analysis of four mercury compounds was proposed. Post column microwave digestion was firstly applied to speciation of mercury and good results were obtained. Three organic mercury compounds was much more rapidly decomposed comparing with the common method. The easy handling of samples and the specificity of the AFS detector made it convenient and no special clean-up steps needed. The proposed method has been successfully applied to determine methylmercury in seafood. The major difficulty of the proposed procedure was the broadening of the peaks caused by the system itself, which probably could be solved by using more capable pumps to deliver the oxidant solution at lower flow rate.

\section{Acknowledgements}

This work was jointly supported by National Natural Science Foundation of China (20137010) and Chinese Academy of Sciences (KZCX2-414). We acknowledge Prof. F.C. Adams for his kindly offering CRM DORM-2 and the Beijing Raileigh Analytical Instrument Co., for loan the AFS.

\section{References}

[1] R.B. Clark, Marine Pollution, Clarendon Press, Oxford, 1986.

[2] Y.-S. Ho, P.C. Uden, J. Chromatogr. A 688 (1994) 107116.

[3] C. Sarzanini, G. Sacchero, M. Aceto, O. Abollino, E. Mentasti, J. Chromatogr. 626 (1992) 151-157.

[4] M.J. Bloxham, A. Gachanja, S.J. Hill, P.J. Worsfold, J. Anal. At. Spectrom. 11 (1996) 145-148.

[5] H. Hintelmann, R.D. Wilken, Appl. Organomet. Chem. 7 (1993) 173-180.

[6] P.B. Stockwell, W.T. Corns, D.W. Bryce, Pittcon ${ }^{\circledR} 2000$ Abstracts, p. 1840.

[7] E. Munaf, H. Haraguchi, D. Ishii, et al., Anal. Chim. Acta 235 (1990) 399-404.

[8] C. Schickling, J.A.C. Broekaert, Appl. Organomet. Chem. 9 (1995) 29-36.

[9] W.J.C. Gaston, Spectrosc. Lett. 24 (1991) 681-697.

[10] F. Palmisano, P.G. Zambonin, N. Cardellicchio, Fresenius' J. Anal. Chem. 346 (1993) 648-652.

[11] R. Falter, G. Ilgen, Fresenius' J. Anal. Chem. 358 (1997) 401-406.

[12] R. Falter, H.F. Schöler, J. Chromatogr. A 675 (1994) 253256.

[13] R. Falter, H.F. Schöler, Fresenius' J. Anal. Chem. 353 (1995) 34-38.

[14] R. Falter, G. Ilgen, Fresenius' J. Anal. Chem. 358 (1997) 407-410.

[15] Y. Cai, G. Tang, R. Jaffé, R. Jones, Int. J. Environ. Anal. Chem. 68 (1997) 331-345.

[16] L.-N. Liang, G.-B. Jiang, J.-T. Hu, Chin. J. Anal. Chem. 29 (2001) 403-405. 